\title{
Implementation of reduced induction machine fuzzy logic control, based on dSPACE-1104 R\&D controller board
}

\author{
Mohamed Moutchou , Atman Jbari ${ }^{2}$, Younes Abouelmahjoub ${ }^{3}$ \\ ${ }^{1}$ Department of Electrical Engineering, National Higher School of Arts and Crafts, Hassan II University, Casablanca, \\ Morocco \\ ${ }^{2}$ Electronic Systems, Sensors and NanoBiotechnology Research Group, Higher school of Technical Education, \\ Mohammed V University in Rabat, Morocco \\ ${ }^{3}$ Department of industrial Science and Technology, National School of Applied Sciences, ChouaibDoukkali University in \\ EL Jadida, Morocco
}

\section{Article Info \\ Article history: \\ Received Sep 5, 2020 \\ Revised Jan 8, 2021 \\ Accepted Mar 25, 2021}

\section{Keywords:}

dSPACE-1104

Fuzzy control

Implementation

Induction machine

Motor drive

Non-linear control

\section{Corresponding Author:}

Mohamed Moutchou

Departement of Electrical Engineering

Hassan II University, National Higher School of Arts and Crafts (ENSAM)

150 Nil Boulevard, ENSAM, Casablanca, Morroco

Email: mohamed.moutchou@univh2c.ma

\begin{abstract}
In this paper, we present our contribution in Induction Machine control field. The control we designed is based on fuzzy logic theory, this choice is motivated by the fact that this technique of control is suitable for the control of systems characterized by its parameters uncertainties and variations. The proposed control is optimized by using a genetic algorithm for fuzzy logic controller (FLC) gains tuning and by a good choice of calculation techniques used in FLC. Three versions of IM fuzzy logic control were validated by simulation. After that in order to be able to experimentally implement this control on dSPACE-1104, we proposed an optimized and reduced structure of the control. The experimental results proof the effectiveness and the satisfied performance of the proposed IM fuzzy control.
\end{abstract}

This is an open access article under the CC BY-SA license.

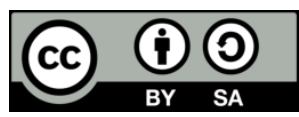

NOTATION

$\Phi_{r},\left(\Phi_{r d}, \Phi_{r q}\right)$

$\left(i_{s d}, i_{s q}\right),\left(v_{s d}, v_{s q}\right)$

$\left(R_{r}, R_{s}\right),\left(L_{r}, L_{s}\right)$

$L_{m}$

$\Omega, P, T_{L}$

$J, f$
Are respectively rotor flux, and flux components in the coordinate (d, q)

Are respectively stator currents and Stator voltages in the coordinate $(\mathrm{d}, \mathrm{q})$

Are respectively rotor and stator resistances and rotor and stator cyclic inductances Mutual cyclic inductance $(\mathrm{H})$

Are respectively rotor speed (rpm) and number of pole pairs, load torque $(\mathrm{Nm})$

Rotor inertia moment $\left(\mathrm{kg} . \mathrm{m}^{2}\right)$ and viscous friction coefficient (N.s/rad)

\section{INTRODUCTION}

When faced with complex control problems, as data uncertainties, unknown perturbations and parameter variations that may taint controlled system, it becomes difficult to design resolution algorithms using classical logical reasoning, an alternative and adapted technique ensuring control robusteness, should be used. Among the techniques advocated in this type of case are techniques based on fuzzy logic, which is capable of providing an acceptable precision solution in appropriate time with reasonable means. Conversely 
to conventional logic reasoning that requires precise knowledge of the data and provides accurate responses, fuzzy logic imitates human reasoning, that is usually based on incomplete and imprecise data, to take approximative decisions.

Fuzzy logic was first proposed by L.A. Zadeh of the University of California, Berkeley, 1965 [1]. Several investigations have been made for the fuzzy logic resolution of various categories of problems deemed difficult. In 1975 Professor Mamdani designed a fuzzy controller for a steam engine [2]. Since then, fuzzy logic has applications in various fields, such as [3]-[13], i) in the automobile: automatic transmissions, injection and antiluetics controls, air conditioning [14], [15], ii) automation of manufacturing processes, iii) instrumentation, recognition of voices, characters and shapes, iv) judgment and consultation, v) Information processing (database, search for information, ...), vi) Systems modeling and control [16]-[17], and vii) motors control [18]-[20].

In this paper we use the advantages of fuzzy logic concept and technique to perform a robust control of the induction machine. The experimental results of the elaborated reduced structure of IM fuzzy control will show the effectiveness of this control. The paper is organized as follow: in first, in Section 2, we present an IM fuzzy-vector control, that need to have a perfect knowledge of the IM in order to be able to perform the (d, q) axis decoupling. Next, in Section 3, we present the reduced IM fuzzy logic control structure, who's improved in term of real time implementation, and finally we give conclusion in Section 4.

\section{FUZZY-VECTOR CONTROL OF THE INDUCTION MACHINE}

\subsection{Induction machine model}

The Induction machine model, given in (1), is established under the assumptions of linearity of the magnetic circuit and neglecting iron losses. This model is expressed in the fixed stator reference frame (d, q), after a transformation given a direct orientation of the rotor flux, so we get: $\Phi \mathrm{r}=\Phi \mathrm{rd}$ and $\Phi \mathrm{rq}=0$, and it can be described as [21]-[25].

$$
\sigma=1-\frac{\mathrm{L}_{\mathrm{m}}^{2}}{L_{r} \cdot L_{S}} ; k=\frac{L_{m}}{\sigma \cdot L_{s} \cdot L_{r}} ; T_{r}=\frac{L_{r}}{R_{r}} ; \gamma=\frac{1}{\sigma \cdot L_{S}} \cdot\left(R_{S}+\frac{R_{r} \cdot L_{m}^{2}}{L_{r}^{2}}\right) .
$$

\subsection{Induction machine fuzzy-vector control design}

The IM Fuzzy-Vector control is performed by using two loops. The inner one is designed by using a vector control technic, and the outer loop is made using a fuzzy logic control technic.

The outer loop ensures the rotor flux and speed regulation using two fuzzy logic controllers (FLC). The Flux-FLC and Speed-FLC provided respectively the direct and quadratic trajectory references. The regulation and control of the stator currents is ensured by two PI regulators. Their design is made by using the transfer functions expressed in (3) and (4), that is obtained after decoupling (d, q) axis variables. The decoupling allows us to establish the equivalent model (1).

$$
\left\{\begin{array}{c}
\frac{d i_{s d}}{d t}=-\gamma \cdot i s_{d}+\frac{v_{s d}^{*}}{\sigma \cdot L_{s}} \\
\frac{d i_{s q}}{d t}=-\gamma \cdot i s_{q}+\frac{v_{s q}^{*}}{\sigma \cdot L_{s}} \\
T_{r} \cdot \frac{\mathrm{d} \Phi_{\mathrm{r}}}{d t}+\Phi_{r}=L_{m} \cdot i_{s q} \\
\omega_{s}=p \cdot \Omega+\frac{L_{m}}{T_{r}} \cdot \frac{i_{s q}}{\Phi_{r}} \\
\frac{d \Omega}{d t}=p \cdot \frac{L_{m}}{J \cdot L_{r}} \cdot\left(\Phi_{r} \cdot i_{s q}\right)-\frac{f}{J} \cdot \Omega-\frac{T_{L}}{J}
\end{array}\right.
$$

From these equations we can determine the functions (2), (3).

$$
\begin{aligned}
& I_{s d}(s)=\frac{V_{s d}^{*}(s)}{\gamma+s} \cdot \frac{1}{\sigma \cdot L_{s}} \\
& I_{s q}(s)=\frac{V_{s q}^{*}(s)}{\gamma+s} \cdot \frac{1}{\sigma \cdot L_{s}}
\end{aligned}
$$

In this section we will present and compare three fuzzy controllers, used in the IM control structure as shown in Figure 1 and whose structure is given in Figure 2. We used triangular-shaped membership functions, as shown in Sub-section 2.3, because of the simplicity of their processing and implementation. In this study we used an approximate calculating method named the gravity center (5) ignoring intersections of 
subsets, in order to reduce computational complexity and ease the implementation, which gave satisfactory and comparable results to those using exact computation gravity center.

$$
g=\frac{\int x \cdot \mu(x) \cdot d x}{\int \mu(x) \cdot d x}
$$

Where: $\mathrm{x}$ is a set member, and $\mu(\mathrm{x})$ its membership function.

We used normalized supports equal to [-1,1] and to scale the inputs and outputs of the fuzzy regulators we used scaling gains, whose the choice has a great influence on the control dynamics. For this reason, we have optimized the choice of the six scaling gains (ge, ged, gdu) of flux FLC and those of speed FLC, by using an optimization method based on genetic algorithm similar, in principle, to that developed and used in our previous paper [26].

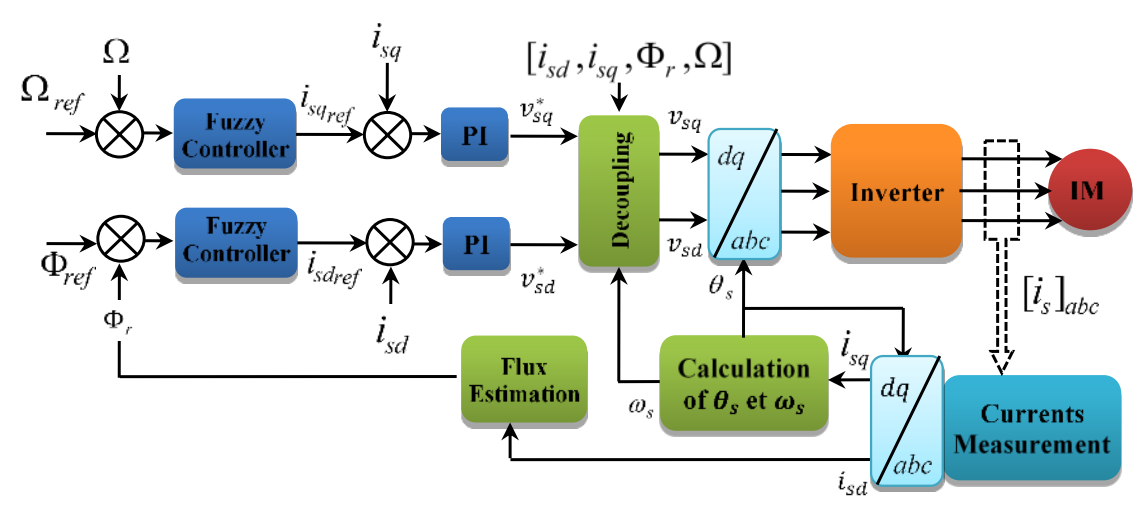

Figure 1. Structure of the induction machine fuzzy-vector control

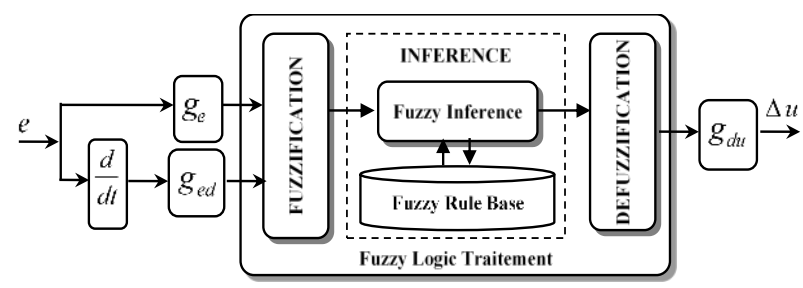

Figure 2. Structure of the fuzzy controller bloc

\subsection{Proposed fuzzy controllers}

In this work we propsed and studied three fuzzy controllers. The three FLC are similar in principle and structure but different in term of linguistic variables numbre. The one uses three linguistic variables, the second uses fives and the third uses seven. In order to not overload the paper and to be more concise, we will present in this section, the third one. We present in Figure 3, the membership function of the output variation, input and input dynamic. In Table 1 we present the linguistic rule basis, and in Figure 4 we present the fuzzy logic control surface that show another presentation of the linguistic rule basis of the FLC.
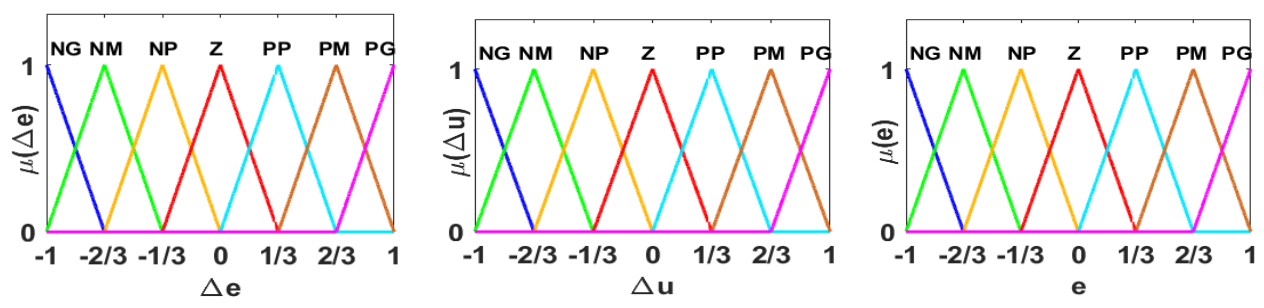

Figure 3. Membership functions of inputs $(\mathrm{e}, \Delta \mathrm{e})$ and output variation $(\Delta \mathrm{u})$ 


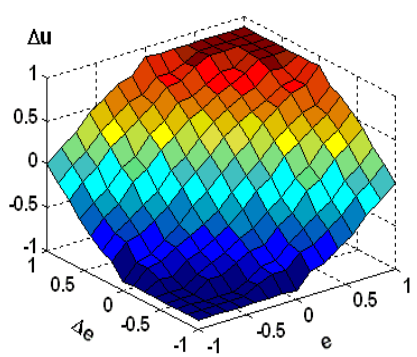

Table 1. Fuzzy regulator linguistic rule basis

\begin{tabular}{|c|c|c|c|c|c|c|c|c|}
\hline & $\mathrm{e}$ & & & & rror & & & \\
\hline$\Delta \mathrm{e}$ & $\Delta \mathrm{u}$ & NL & NM & $\mathrm{NS}$ & $\mathrm{Z}$ & PS & PM & PL \\
\hline & $\mathrm{NL}$ & NL & NL & NL & NL & NM & NS & Z \\
\hline$\cdot \tilde{g}$ & $\mathrm{NM}$ & NL & NL & NL & NM & NS & Z & PS \\
\hline & NS & NL & NL & NM & NS & Z & PS & PM \\
\hline 58 & Z & NL & NM & NS & Z & PS & PM & PL \\
\hline & PS & NM & NS & Z & PS & PM & PL & PL \\
\hline 氠 & $\mathrm{PM}$ & NS & Z & PS & PM & PL & PL & PL \\
\hline & PL & Z & PS & PM & PL & PL & PL & PL \\
\hline
\end{tabular}

Figure 4. Fuzzy control surface

\subsection{Simulation study results}

In this study, we are going to compare the three previously proposed fuzzy controllers, by performing several simulations on Matlab, in order to choose the appropriate fuzzy controller in terms of control performance and execution speed. The IM parameters used in this paper are given in Table 2.

Table 2. The induction machine parameters

\begin{tabular}{llll}
\hline Parameters & & Values & Units \\
\hline Rated power & $\mathrm{P}$ & 1.5 & $\mathrm{~kW}$ \\
Voltage & $\mathrm{U}$ & 400 & $\mathrm{~V}$ \\
Rated current & $\mathrm{I}$ & 3.4 & $\mathrm{~A}$ \\
Rated speed & $\mathrm{n}$ & 1423 & $\mathrm{rpm}$ \\
Stator Resistance & $\mathrm{Rs}$ & 5.7 & $\Omega$ \\
Rotor Resistance & $\mathrm{Rr}$ & 3.4 & $\Omega$ \\
Mutual Inductance & $\mathrm{Lm}$ & 0.211 & $\mathrm{H}$ \\
Stator Inductance & $\mathrm{Ls}$ & 0.2223 & $\mathrm{H}$ \\
Rotor Inductance & $\mathrm{Lr}$ & 0.2223 & $\mathrm{H}$ \\
Motor inertia & $\mathrm{J}$ & 0.018 & $\mathrm{~kg} . \mathrm{m}^{2}$ \\
Viscous friction coefficient & $\mathrm{f}$ & 0.007 & $\mathrm{~N} . \mathrm{s} / \mathrm{rad}$ \\
Number of pole pairs & $\mathrm{p}$ & 2 & \\
\hline
\end{tabular}

Figure 5 shows the simulation results of the three induction machines fuzzy controls using the same control structure as in Figure 1 and different fuzzy controllers, the first uses the fuzzy 3 -subassembly controller (Figure 5 (a)), the second one uses the 5 subsets (Figure 5 (b)) and the third uses the 7 subsets (Figure 5 (c)), we find that their behavior is very close, showing good performance. In fact, we can see, in case of 7 subsets FLC (Figure 5 (c)), that the speed response is perfect in term of precision and dynamic tracking, and the 3 subsets FLC (Figure 5 (a)) presents same precision performance and acceptable and very small overshoots at $0.05 \mathrm{~s}$ and $1 \mathrm{~s}$ time. The figure 6 , also shows that the three FLC types give the same good flux response. Also, in case of torque response, we can see that the 3 subsets FLC offers good response, except short and small oscillations at $1 \mathrm{~s}$ time, where the load torque changes from 0 to $10 \mathrm{Nm}(10 \mathrm{Nm}$ represents $100 \%$ of rated torque).

Using the same induction machine model for the simulation of the three commands we have noted the following execution times, a) 7.4s in case of using the FLC with 3 subassemblies, b) 14.56s in case of using a FLC with 5 subassemblies, and c) $27.7 \mathrm{~s}$ in case of using a FLC with 7 subassemblies. 

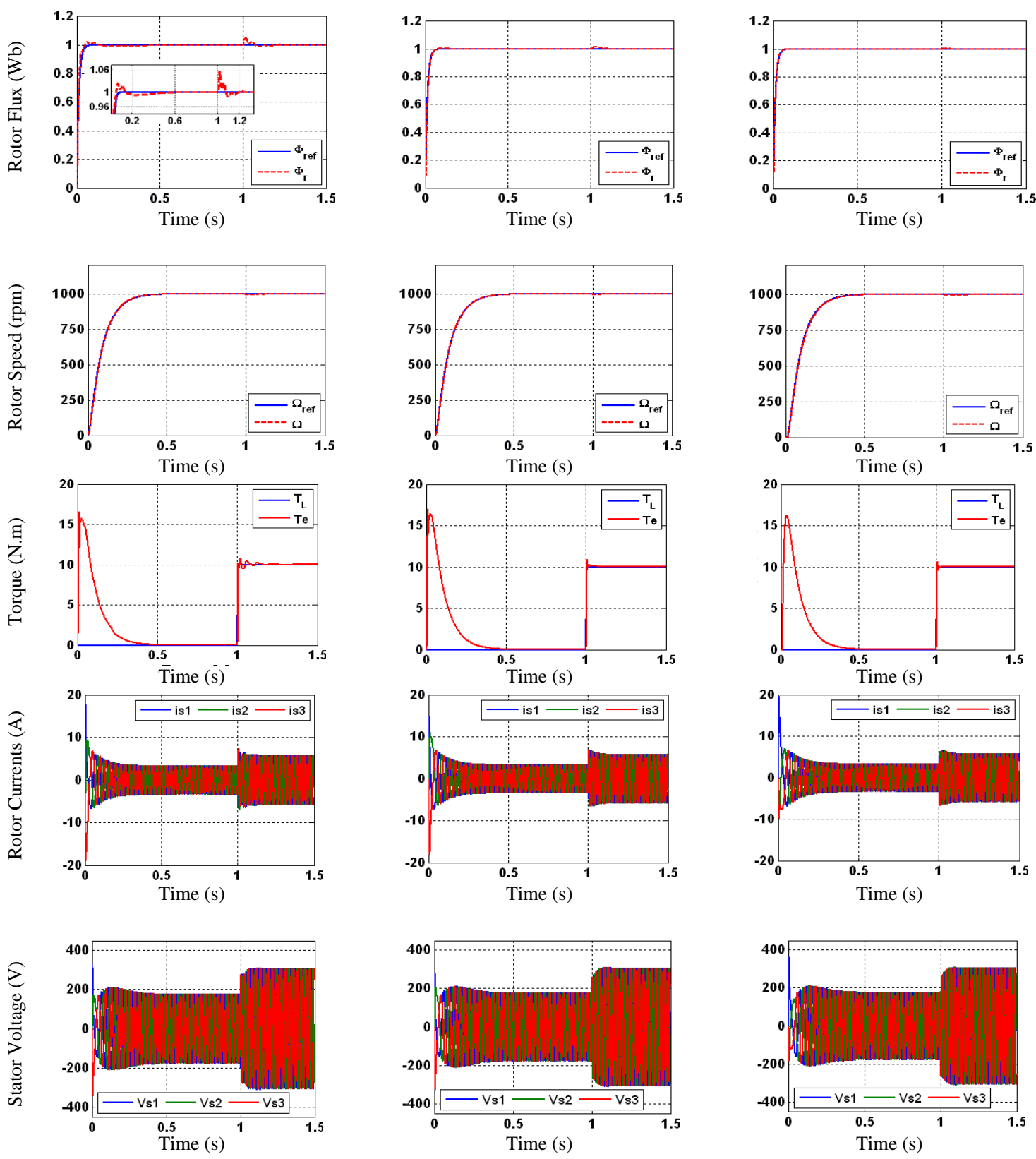

(a)

(b)

(c)

Figure 5. Study of the IM control responses in case of three FLC versions, (a) responses of the IM control in case of 3 sets FLC, (b) responses of the IM control in case of 5 sets FLC, (c) responses of the IM control in case of 7 sets FLC

\section{INDUCTION MACHINE FUZZY CONTROL WITH REDUCED STRUCTURE}

\subsection{Structure of the control}

The fuzzy control proposed in Figure 1 can be reduced to have the structure of the Figure 6, where it can be seen that the decoupling block and the current regulators are no longer used. This idea of reduction has been motivated and induced by our wish to implement the IM control on the dSPACE 1104 board of the test bench. Which does not allow the IM control execution in real time and without overruns when using the previous structure of the Figure 1.

In order to facilitate the implementation and make the control algorithm feasible in the case of our computing unit, we used fuzzy minimal structure regulators, using fuzzy subsets with 3 linguistic variables, and we used the method of weighted averages for defuzzification, which further reduces computing time. We find that the first one is 2 times faster than the 2nd one and 4 times faster than the 3rd one. 


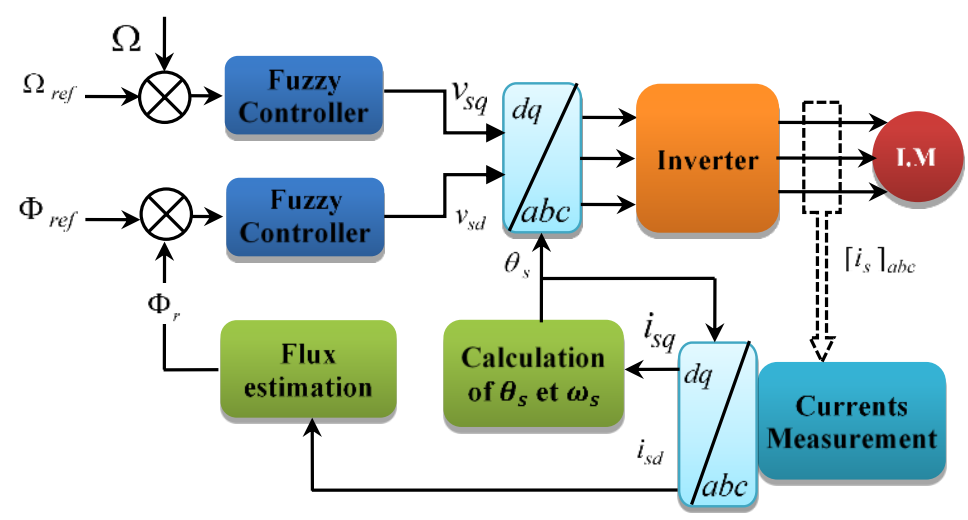

Figure 6. Reduced structure of the fuzzy control of the asynchronous machine

\subsection{Implementation of the experimental tests of the control}

For the experimental validation of this command, we used the structure of Figure 7, that presents the main elements of our test Bench. The test bench is constituted as shown in the figures Figure 8 and Figure 9, of an IM of $1.5 \mathrm{~kW}-230 \mathrm{v} / 400 \mathrm{~V}$ (Table 2) coupled to a DC Machine of $1,5 \mathrm{~kW}$ and using encoder of 1000 ppr, a dSPACE DS1104 R\&D Controller Board integrated in a computer and accessible via a connection panel, A SEMIKRON "SKM 50GB 123 D" type three phases inverter, a card for interfacing the MLI commands that are destinated to the inverter, a card comprising the stator current sensors, and A filters card for measured currents. The purpose of these tests is to prove, i) the possibility of real-time execution of this command, ii) the effectiveness of this command which is characterized by its reduced structure, and iii) that the reduction in the structure of the order does not affect the performance of the fuzzy control of IM.

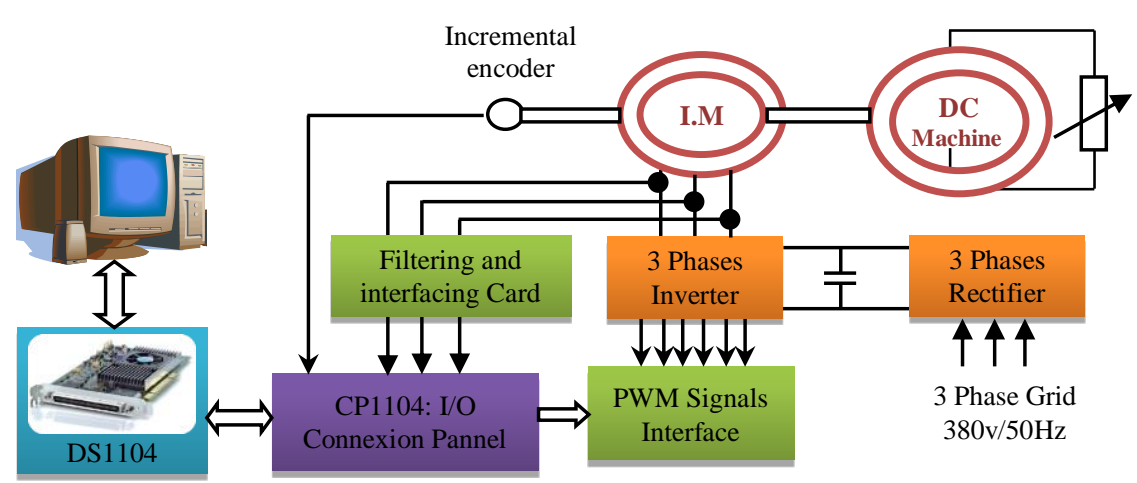

Figure 7. Structure of the test bench used for the control experimental validation

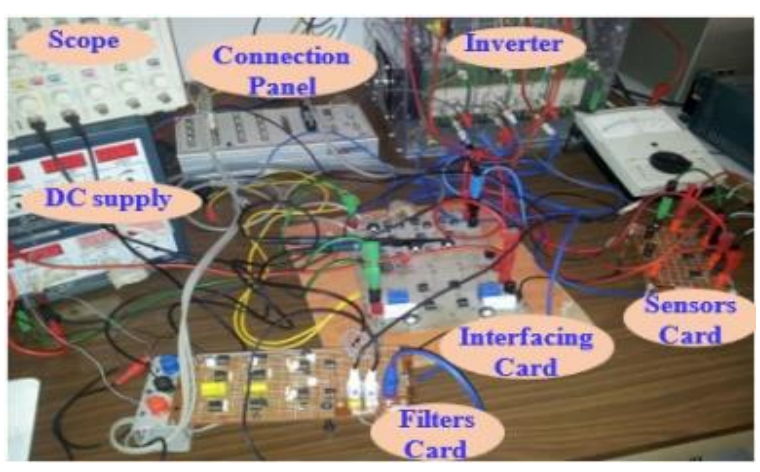

Figure 8. Test bench picture

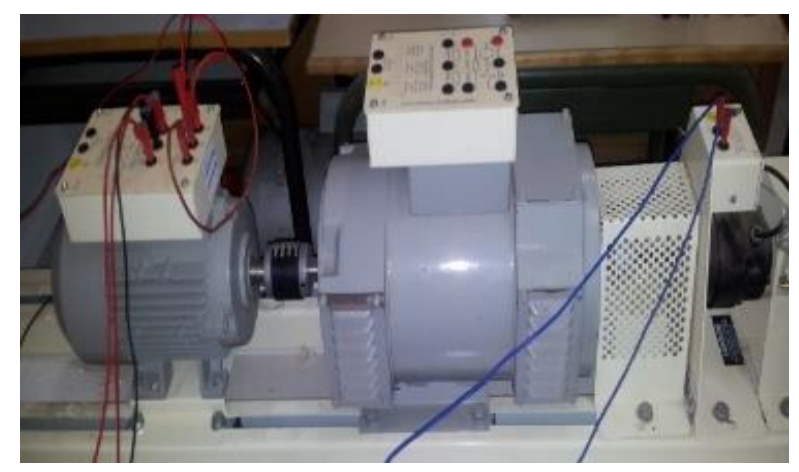

Figure 9. The induction machine and DC Machine 
The implementation of the command in the DS1104 card is made directly from the MATLAB environment. We chose to use a sampling frequency of $10 \mathrm{khz}$ and the ode 1 solver corresponding to the Euler method of discretization, these choices are appropriate and adapted to the calculation power limit of the DS1104 card. And to ensure in same time a good PWM control of the inverter and good measurement of the stator currents, we used a carrier frequency of the PWM, equal to $5 \mathrm{khz}$. To reduce disturbances and the peaks that affect the measurement of stator currents, we have chosen to synchronize the currents measurement with the PWM control signals. The execution, shutdown and supervision of the I.M fuzzy control algorithm is carried out by using the graphical interface realized and executed by using the ControlDesk software, which allows us to parameterize the tests we want to perform in real time, and also to record the results of these experimental tests.

\subsection{Experimental results}

The first test given in Figure 10, shows the behavior of the IM during its excitation, it shows the IM response in case of a flux reference step with a zero-speed reference and null load torque, where we can see that the flux correctly and rapidly follows its reference.

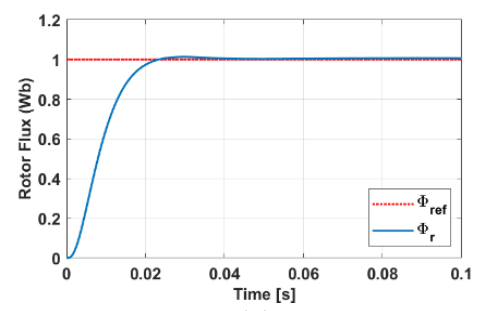

(a)

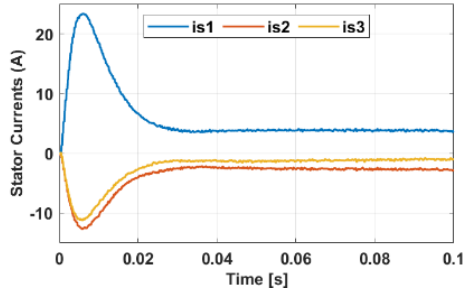

(b)

Figure 10. Flux response for $\Omega_{\text {ref }}=0$ and $\mathrm{T}_{\text {Load }}=0$

Figure 11 shows the responses of rotor flux, stator currents, speed and torque when applying a speed step of $1000 \mathrm{rpm}$ under load torque, we can see that this has a small effect on the flux and that the speed reaches its reference with a response time $<0.2 \mathrm{~s}$. We also see that the stator currents and torque remain below the limits of IM. In Figure 12, we can see that the IM presents a good dynamic behavior when applying a square-shaped speed reference of $\pm 500 \mathrm{rpm}$, and we notice also that the flux is weakly influenced by the changes of the IM rotation direction.

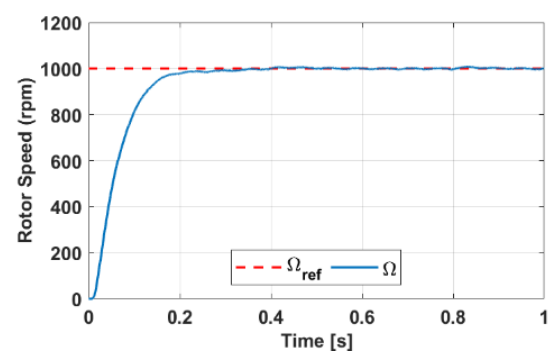

(a)

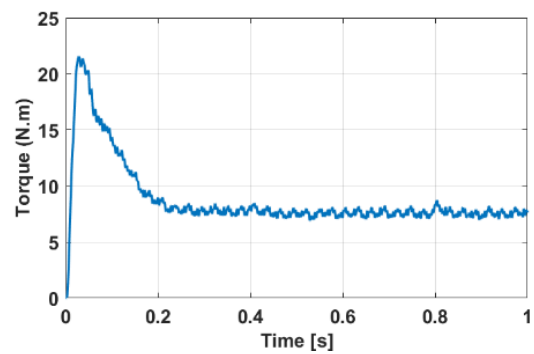

(c)

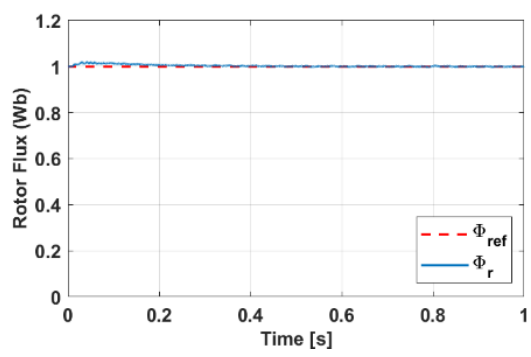

(b)

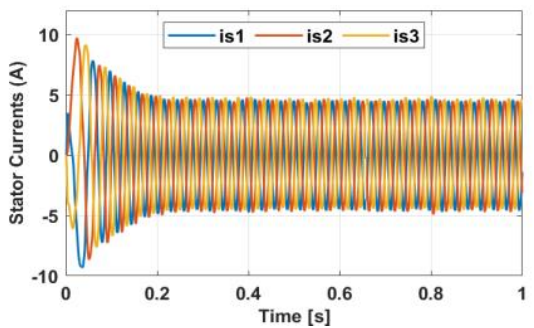

(d)

Figure 11. Responses for step reference speed $\left(\Omega_{\text {ref }}=1000 \mathrm{rpm}\right)$ 


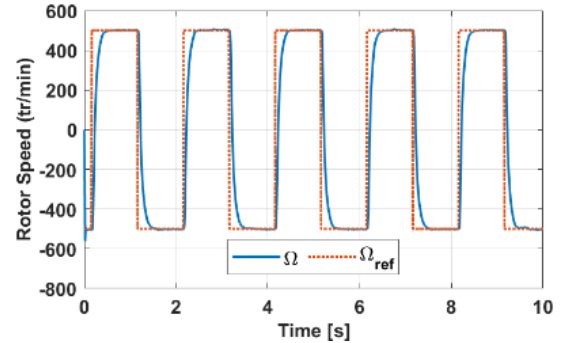

(a)

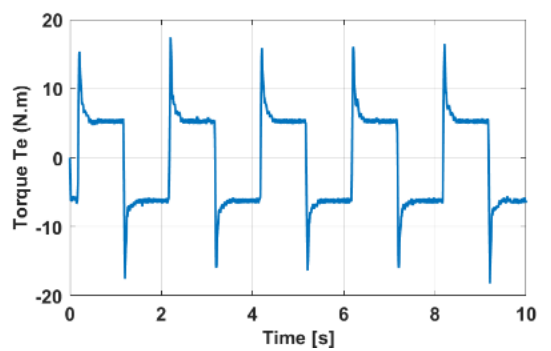

(c)

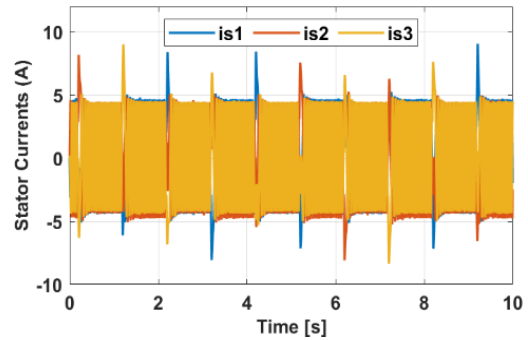

(b)

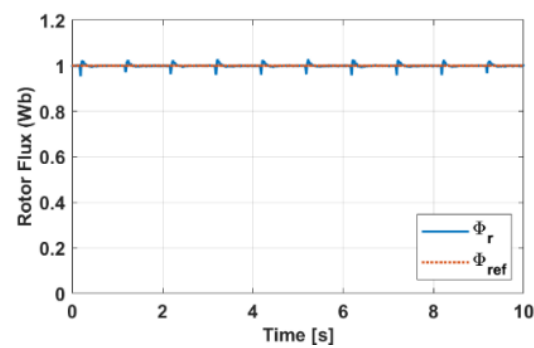

(d)

Figure 12. Responses in case of a square form of speed reference form $\Omega_{\text {ref }}= \pm 500 \mathrm{rpm}$

\section{CONCLUSION}

In this work, we have proposed, in first, a fuzzy-vector control of the induction machine, the simulation was made in order to evaluate the control performances and to test three degrees $(3,5$ and 7$)$ of fuzzy logic controllers. This control gives acceptable performance for three degree's FLC, and very good response in case of FLC of seven degree. The real-time implementation of this control, on dSPACE-1104 board was impossible, due to overrun problems. In order to resolve this problem, we have proposed a reduced fuzzy control structure based on simplified and optimized fuzzy controllers that give a good control characteristics and faster calculation, established after a study that showed through simulation that this structure reduction of FLC does not significantly affect the results obtained. The control structure reduction and optimization has made the implementation possible on our dSPACE-1104 board and realizable in real time, whose experimental results of several and various test, have proved its effectiveness in terms of time response, precision, stability and respect of physical limits of the IM.

\section{REFERENCES}

[1] L.A. Zadeh, "Fuzzy sets," Inf Control, vol. 8, no. 3, June 1965, pp. 338-353, DOI: 10.1016/S0019-9958(65)90241$\mathrm{X}$.

[2] E. Mamdani, "Application of fuzzy algorithms for control of simple dynamic plant," Proc. Inst. Electr. Eng., UK, vol. 121 , no. 12 , pp. 1585-1588, 1974, DOI: 10.1049/piee.1974.0328.

[3] P. King and E. Mamdani, "The application of fuzzy control systems to industrial processes," Automatica, vol. 13, no. 3, pp. 235-242, 1977, DOI: 10.1016/0005-1098(77)90050-4.

[4] R. Babuska and E. Mamdani, "Fuzzy control," Scholarpedia, vol. 3, no. 2, p. 2103, 2008.

[5] A. Ibrahim, "Fuzzy logic for embedded systems applications," Amsterdam: Newnes, 2004.

[6] G. Klir and B. Yuan, "Fuzzy sets and fuzzy logic," Upper Saddle River, N.J.: Prentice Hall PTR, 1995.

[7] L. Zadeh, G. Klir and B. Yuan, "Fuzzy sets, fuzzy logic, and fuzzy systems," Singapore: World Scientific, 1996.

[8] C. Alavala, "Fuzzy logic and neural networks," New Delhi: New Age International (P) Ltd., Publishers.

[9] F. Chevrie and F. Guély, "Cahier Technique N¹91: La logique floue," 1st ed. Groupe Schneider., 1998, pp. 1-30.

[10] Ali M. Eltamaly, A. I. Alolah, and Basem M. Badr, "Fuzzy controller for three phases induction motor drives", Autonomous and Intelligent Systems (AIS) 2010 International Conference on, 2010, pp. 1-6, DOI: 10.1109/AIS.2010.5547020.

[11] Tewari, A. Tripathi, and S.P. Das, "A fuzzy logic controller based indirect field-oriented induction motor drive system," Industrial Technology 2000. Proceedings of IEEE International Conference on, vol. 2, nol. 1, pp. 359-364 2000, DOI: 10.1109/ICIT.2000.854182. 
[12] Jianli Jing, Yanchun Wang, and Yinghui Huang, "The fuzzy-PID control of brushless DC motor," 2016 IEEE International Conference on Mechatronics and Automation, 2016, pp. 1440-1444, DOI: 10.1109/ICMA.2016.7558775.

[13] S.S.M. Verma, S.P. Verma, "Implementation of a fuzzy logic speed controller for electric vehicles on a 32-bit microcontroller", Power Electronics and Drive Systems 2003. PEDS 2003. The Fifth International Conference on, vol. 2, pp. 1004-1009, DOI: 10.1109/PEDS.2003.1283107.

[14] C. von Altrock, B. Krause, and H.-J. Zimmerman, "Advanced fuzzy logic control of a model car in extreme situations," Fuzzy Sets and Systems, vol. 48, no. 1, pp 41-52, 1992, DOI: 10.1016/0165-0114(92)90250-8.

[15] T. Yoshimura, K. Nakaminami, M. Kurimoto, and J. Hino, "Active suspension of passenger cars using linear and fuzzy-logic controls," Control Engineering Practice, vol. 7, no. 1, pp. 41-47, 1999, DOI: 10.1016/S09670661(98)00145-2.

[16] M. Reza Emami, Andrew A. Goldenberg, and I. Burhan Türksen, "Fuzzy-logic control of dynamic systems: from modeling to design," Engineering Applications of Artificial Intelligence, vol. 13, no. 1, pp 47-69, 2000, DOI: 10.1016/S0952-1976(99)00031-7.

[17] Tamer Abdelazim, and O. P. Malik, "Identification of nonlinear systems by Takagi-Sugeno fuzzy logic grey box modeling for real-time control," Control Engineering Practice, vol. 13, no. 12, pp 1489-1498, 2005, DOI: 10.1016/j.conengprac.2005.03.009.

[18] Salima Lekhchine, Tahar Bahi, and Youcef Soufi, "Indirect rotor field oriented control based on fuzzy logic controlled double star induction machine," International Journal of Electrical Power \& Energy Systems, vol. 57, pp. 206-211, 2014, DOI: 10.1016/j.ijepes.2013.11.053.

[19] A. Rajendran, and B. Karthik, "Design and analysis of fuzzy and PI controllers for switched reluctance motor drive," Materials Today: Proceedings, vol. 37, Part 2, pp. 1608-1612, 2021, DOI: 10.1016/j.matpr.2020.07.166.

[20] Rakesh Goswami, and Dheeraj Joshi, "Performance review of fuzzy logic based controllers employed in brushless DC motor,” Procedia Computer Science, vol. 132, pp. 623-631, 2018, DOI: 10.1016/j.procs.2018.05.061.

[21] M. Moutchou, M. Hamlich and A. Bakouri, "Robust adaptive backstepping control of the induction machine, using parallel rotor resistance and stator resistance observer," Smart Application and Data Analysis for Smart Cities (SADASC'18), May 28, 2018, DOI: 10.1016/j.procs.2018.05.061.

[22] M. Moutchou, A. Abbou, and H. Mahmoudi, "Induction machine speed and flux control, using vector-sliding mode control, with rotor resistance adaptation," International Review of Automatic Control (Theory and Applications), vol. 5, no. 6, pp. 804-814, November 2012.

[23] J. Lesenne, F. Notelet, and G. Seguier, "Introduction à l'électrotechnique approfondie," Technique et Documentation, 1981, 247p.

[24] G. Séguier and F. Notelet, "Electrotechnique industrielle," Paris: Tec et doc, 1994.

[25] G. Sturtzer and E. Smigiel, "Modélisation et commande des moteurs triphasés," Paris: Ellipses-Marketing, 2000.

[26] M. Moutchou, H. Mahmoudi, and A. Abbou, "A new technique of backstepping control parameters determination using genetic algorithm," Proceedings of International Renewable and Sustainable Energy Conference, IRSEC, 2014, DOI: 10.1109/IRSEC.2014.7059744. 